From victims to actors: the role of children and young people in flood recovery and resilience

Maggie Mort, Marion Walker, Alison Lloyd Williams, Amanda Bingley*,

Dept of Sociology, *Division of Health Research, Lancaster University, Lancaster LA1 4YT, England; e-mail: m.mort@lancaster.ac.uk 


\title{
From victims to actors: the role of children and young people in flood recovery and resilience
}

\author{
Abstract \\ Following a series of recent devastating storms across England with large numbers of \\ homes and businesses evacuated, and despite widespread consensus that further severe \\ flooding is expected, a large section of the population continues to be excluded from \\ developments in flood risk management. We argue that the absence of children and \\ young people from assessments of both the effects of flooding and ways in which it can \\ be mitigated, undermines the effectiveness and legitimacy of policy making. Drawing on \\ in-depth participative research with two groups of flood-affected children and young \\ people we show the range of ways in which they are affected by flooding, some ways they \\ can be better supported, and then how their valuable experience can help shape positive \\ change in policy and practice before, during and after floods. Children developed Flood \\ Manifestos for Change in a direct challenge to their omission from flood governance. The \\ Manifestos and the steps children took to advocate for them can be seen as acts of \\ citizenship, highlighting the capacities of children and young people as flood actors, rather \\ than flood victims.
}

\section{Keywords}

Flooding, children, participation, resilience, citizenship, governance 


\section{Introduction}

Ruth: It feels good. It feels like we finally have a voice.

Sara: Yeah, like we can be heard now; like, they know how we feel.

Devastating storms across the UK between 2005 and 2016 caused large numbers of homes and businesses to be evacuated. Yet despite widespread consensus that further severe flooding is expected, a large section of the population continues to be excluded from developments in flood risk management. In this paper, we argue that the absence of children and young people from assessments of both the effects of flooding and ways in which it can be mitigated, undermines effective and legitimate policy making. After giving some background we draw on in-depth participative research with two groups of floodaffected children and young people to show the range of effects which the disasters had in their lives. We then outline some ways in which flood-affected children can be better supported, before detailing how they used their knowledge and experience to advocate for positive changes in policy and practice before, during and after floods. Taking on an active rather than passive role, the children's 'Flood Manifestos for Change' are a demonstration of children's agency and constitute we believe, a direct challenge to address key omissions in the governance of floods and emergencies. ${ }^{1}$

\footnotetext{
${ }^{1}$ We use the term 'children' to refer to all those we worked with (6-15 years). However, in instances where the text applies to only 11-15 year olds, we use the term 'young people'.
} 


\section{Background}

Over the last decade, more than 250 million people globally were affected by disasters each year - more than half were children (IFRC, 2010). In the UK, coastal and inland flooding tops the National Risk Register with more than five million properties (one in six) at risk in England alone (Cabinet Office, 2015) and there is widespread consensus that more severe flooding is expected over the coming years (IPCC, 2014; Messling et al, 2015). Disasters such as flooding not only affect children's basic right to life, the right to the enjoyment of the highest attainable standard of health and the right to education, but there is an impact on children's right to participate and for decisions to be made in their best interests (OHCHR, 1989).

As a large proportion of the affected population in any emergency, children should be at the heart of planning, response and recovery programming. Yet children are more likely to be seen as disaster victims than as environmental actors (Stephens, 1996; James 2011; Gibbs et al 2013) and even where government agencies express interest in involving them, in practice this is found to be superficial (Freeman \& Aitken-Rose 2005). Children in England and globally are missing, virtually invisible to flood and emergency planning policy and practice (Mellor et al, 2014; Rodriguez-Giralt et al, 2016). Where they are mentioned, children are generally positioned either as vulnerable or, paradoxically, as inherently resilient and likely to simply 'bounce back' (Fothergill and Peek, 2015). Both these perspectives risk ignoring the ways in which children experience and act in emergency situations. This in turn can lead to children's insights being overlooked, in particular relating to how their communities can be supported to recover from and prepare for disasters. 
Children are acutely affected during and after floods. Flood events and the long and protracted recovery period have a significant impact on children's physical and emotional wellbeing (Walker et al, 2012; Whittle et al, 2012). We know from Butler et al's 2016 study of (adult) public and stakeholder perceptions of the UK's 2013/4 floods that those residents who had been evacuated from their homes reported significantly poorer health and wellbeing, and many of those affected are families with children. Floods affect children's day-to-day lives, and can result in many forms of displacement such as having to leave their homes, staying in unsuitable or damp housing, or being unable to attend their usual school. If they are displaced, they may lose friendship networks, school connections, and familiar surroundings. At the same time, they see adults under great strain and they can develop anxiety about future flooding. Children lose important material and spatial 'goods'; they lose sleep and recreation, access to fresh food. They experience fear, anxiety, increased poverty, unfairness, destruction, uncertainty and the feeling of being ignored or misunderstood (Walker et al, 2010; Walker et al 2011).

Within England there remains a general lack of acknowledgement of children's capacities to contribute to and support their local communities in emergencies, as seen in a range of key government documents (HM Government, 2004; DCMS, 2006; EAC, 2016). Current flood related and emergency planning policy (e.g. Public Health England, 2014) either ignores children or positions them as 'vulnerable', along with older people and pets, which has the effect of patronising and further disenfranchising children. Recently published guidance on flood resilience either makes no mention at all of children and young people (Defra, 2016) or takes a step forward in acknowledging them and advocating their involvement "wherever possible", but still under the category of 'vulnerable' (Cabinet Office, 2016, page 4). 
Most research into the social consequences of contemporary flooding has not included the perspectives of children. A notable exception is the landmark seven-year study with children following Hurricane Katrina (Fothergill and Peek, 2015). This ground breaking ethnographic work follows in great detail children's recovery 'trajectories' (which are anything but linear) as they move through the vagaries of post flood life, heavily shaped by multiple forms of deprivation and by class, race and gender. Fothergill and Peek's work also demonstrates the value of forms of participation to children's recovery as this has the effect of reducing anxiety and enhancing a sense of control. Beyond flooding, participatory research with children who had experienced the Christchurch New Zealand 2010/11 earthquakes has shown that where space and time were given to enable the emotional processing of what had happened, children were able to show, illustrate and document the disaster. This work enabled the assembling of both the personal and community histories of the earthquakes, contributing to community recovery (Mutch and Gawith 2014). Further, it is reported that when children became involved in environmental monitoring following the Chernobyl disaster this resulted in both improved clean-up rates and a lessening in the "psychic numbing' which had been observed in the wake of the crisis (Zhirina in Stevens, 1996).

There is evidence that children can be agents of change within their communities and capable of actively participating in decision-making and emergency planning activities that help protect themselves, their families and communities. The Duke of Cornwall Community Safety Award, set up after the 2010 UK floods is open to ages 5-18 and more than 18,000 young people have completed this (Cornwall Council, 2012). International examples of children's involvement in community recovery include El Salvador, where severe flooding in 2008 led to the deaths of 12 people. Following those floods, children became involved in the 
disaster preparedness process, leading to a drastically improved capacity to respond quickly and efficiently following similar flooding in 2009 (Back et al, 2009). Yet despite evidence of the benefits of children's participation in disaster risk reduction and emergency planning, Rodriguez et al's (2016) scoping review of both practice and research shows that this remains disappointingly rare (see the European Commission Horizon 2020 CUIDAR project: Cultures of Disaster Resilience Among Children and Young People). Some recognition of the need to work with children has emerged in the UK, e.g. the Essex Resilience Forum 'What if...?' programme, which uses interactive games designed to help children think about what to do in emergency situations (Essex Civil Protection \& Emergency Management, 2014), and the recently published Cumbria Flood Action Plan that includes an entry on working with flood-affected children (Environment Agency \& Cumbria Partnership, 2016).

There is a strong argument for the value of post flood participatory research with affected groups. 'Flood apprentices' gained prominence for positive effects on community engagement and resilence building (Whatmore and Landstrom, 2011). Easthope's ethnographic study of community participation in, and transformation of, national recovery and resilience guidance in flooded Toll Bar, South Yorkshire demonstrated the power of local actors to mobilise their experience (Easthope and Mort, 2014). The longitudinal 'recovery diaries' produced by 44 adults in Hull following the 2007 severe flooding demonstrated a 'flood recovery gap' in that for many people the recovery process is more gruelling than the flood 'itself' (Medd et al, 2014). This diary based research with families in Hull post 2007 revealed the marginalisation of childen and led to the development of the Hull Children's Flood Project (2009-11) which uncovered concerns about the effects of flooding on children's longer-term physical and emotional health and wellbeing and led to 
calls for further work in this area (Walker et al, 2010; 2012). The project we report on here takes that call a step further to explore how children's flood experiences, the actions they take and the advocacy they carry out can explicity inform policy development.

Our research concerned children's experiences of the UK winter 2013/14 floods and was carried out in collaboration with Save the Children. We employed creative participatory methods specifically to enable flood-affected children to articulate their experiences and shape a more productive relationship with relevant agencies and adults. We aimed to understand children's experiences of the flooding, the impact on their lives, their resilience and the longer-term recovery process; to discover how children can best be supported in a flood and how to enhance their resilience to future emergencies; and to influence emergency policy and practice to better meet the needs and build the resilience of children.

The children who took part are located in geographically and socioeconomically contrasting English locations and experienced very different types of flooding:

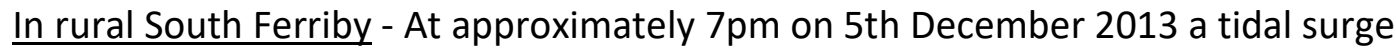
breached the banks of the River Humber, damaging homes, businesses and farmland. The tidal surge travelled three kilometres inland and was the highest ever recorded in the Humber (Thorne 2014). More than 100 families in the community were flooded and a third of the children attending the local primary school were affected.

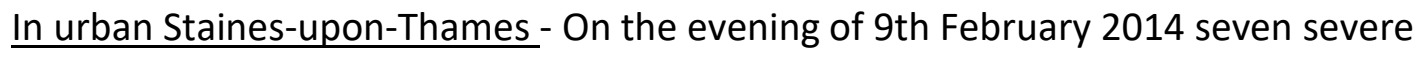
flood warnings were put in place for the River Thames in north Surrey. Residents were evacuated and roads and schools were closed. Within days the Government declared a state of emergency with the army drafted in to assist the emergency 
services. Surrey experienced 'coincident' flooding i.e. clusters of events involving tidal, rainfall, river and groundwater sources, a hallmark of the winter 2013/14 floods (Thorne, 2014).

Between these locations we worked with a total of 30 children and 11 adults (parents, teaching staff and community members): 15 children aged 6-12 in South Ferriby (and 4 adults) and 15 young people aged $11-15$ in Staines-upon-Thames ${ }^{2}$ (and 7 adults). ${ }^{3}$ Initial conversations were held with the schools where it was agreed to issue a general invitation across the year groups so that any child who identified as flood-affected and wanted to take part was able to indicate interest. Infomed consent was then obtained from parents/carers who were also invited to take part in order to reassure families in case of distress (only a small number of parents took part, mostly of the younger children, but other adults gave us intervews which were used as background data/information for the study).

\section{Methodology}

Our research approach was influenced by the work of disaster sociologist Kai Erikson who has argued that those who have experienced disaster develop a particular world view, where that world is less safe and secure. His work attends to issues of trust in authority and collective identity and is particularly concerned with the way disasters can both destroy and create community. Because of their experience and their altered world view Erikson argues that people who experience disaster deserve to be listened to very carefully (Erikson, 1978; 1994; 2008). Erikson argues that chronic conditions, as well as acute events can induce

\footnotetext{
${ }^{2}$ Hereafter 'Staines'

3 The children's ages are given from when they started the project. All participants are referred to by their pseudonym.
} 
trauma and especially when people are left out, abandoned from "the life around them" (page 21,1978$)$. In the case of the Buffalo Creek flood and landslip disaster Erikson refers to people "too old" to take part; so we ask, what about those considered too young to take part? And if experience is integral to learning as argued by Lave and Wenger (1991) then those developing policy need to draw more directly on the acquired and embodied expertise of disaster survivors regardless of age.

There are significant ethical issues involved when working with children who have experienced major disruption. These include concerns about re-traumatisation and ongoing problems in a context of limited resources for support in school and within the community. There is also the need for a stringent ethical review process, which may help to explain the lack of studies seeking to understand children's perspectives on disaster. We argue that 'conventional' and less participatory social research methods such as interviews and questionnaires, which might be used with adults, are less appropriate with disaster-affected children because such methods are less likely to create a familiar, comfortable and facilitative environment for meaningful inquiry. ${ }^{4}$

Our methods were designed to allow the children to voice their experiences and facilitate the sharing of their thoughts in a safe environment and the project began nine months after the floods. We developed a creative, interactive programme for working with flood-affected children drawing on well-documented, sensory-based approaches, in particular practised by Bingley (2003; see Bingley and Milligan, 2007 for description and discussion of this arts-

\footnotetext{
${ }^{4}$ Approval was gained from the Lancaster University Research Ethics Committee on 16.09.14 no 51389.
} 
based methodology with children). We started by inviting the children to share their individual stories and then in groups moved towards the collective story, from which ways of recovering and building resilience as a community could be developed. Three all-day workshops held over the course of the school year in a familiar space near, but outside of the school environment, were key to enabling this process and building towards a public sharing of the project.

The workshops were framed with drama games and exercises, designed to establish a sense of trust among the group, as not all the children knew each other, to 'warm up' particular skills needed for the workshops and to open up a safe space in which to share stories. The children then walked with us around their local landscape affected by the flood, showing us places and features they felt were significant. Each was given a digital camera so they could record traces of the flood (Figure 1). Back at the workshop, the children shared their photographs in group 'phototalk' sessions. They were then invited to use arts-based techniques including sandplay, 3D modelling with art and found materials, and as they worked with these materials they told more of their stories, articulating experiences of the flood. ${ }^{5}$ Theatre based methods used throughout the workshops aimed to build the children's sense of themselves as flood 'actors' and develop their confidence to be able later to share their experiences and ideas with wider audiences, locally, regionally and nationally.

\footnotetext{
${ }^{5}$ As the workshops progressed, some children said they wanted us to 'interview' them, so we conducted a small number of these, but this was not the primary approach.
} 


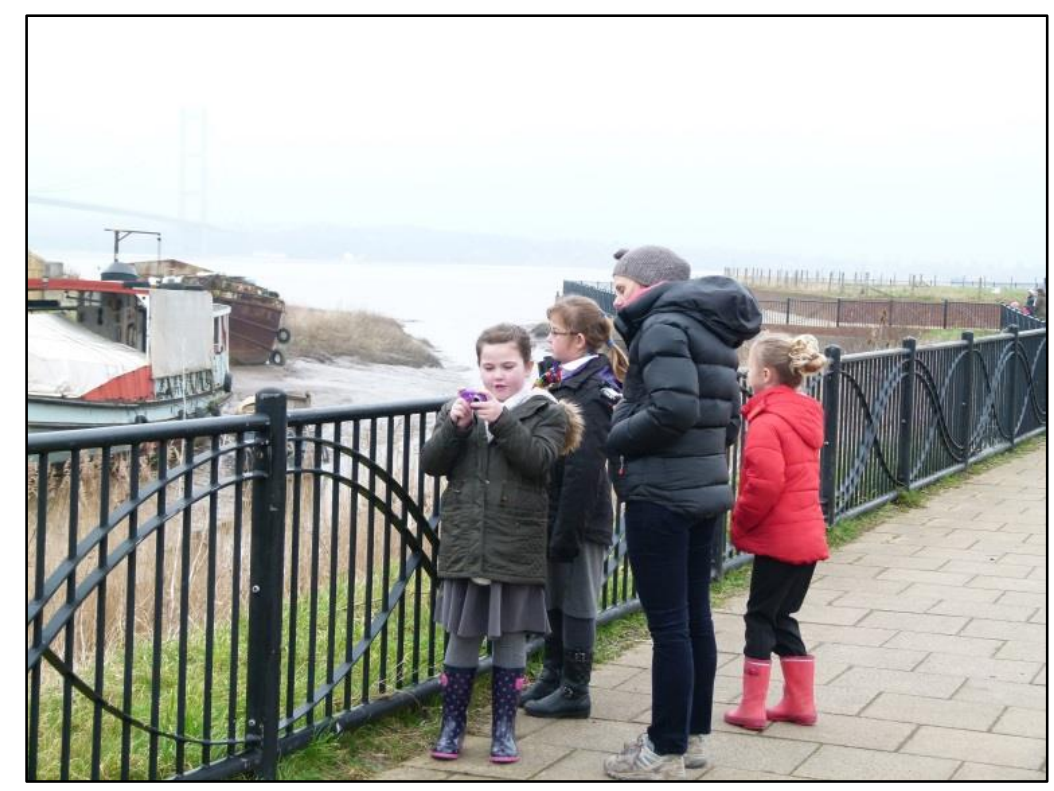

Figure 1. Walking and photographing the local landscape

Data collected during workshops included: photographs; video and audio recordings of walking and phototalk sessions; group discussions during sandplay, 3D modelling and theatre activities and interview transcripts. Audio recordings were transcribed. This multimedia material was coded and categorised thematically in research team meetings and organised using Atlas.ti software. Emerging themes were taken back to the children for discussion and to support the development of their later presentations to stakeholders and creation of their Flood Manifestos for Change.

\section{Six major themes}

\subsection{Children's reactions to warnings and the need for greater flood awareness}

Both groups of children indicated widespread confusion about flood warning systems. It appeared their families did not receive warnings about the flood or, if they did, then did not take action. As a result, when the flood happened people were unprepared. Families in 
South Ferriby were taken by surprise by the speed of the tidal surge and had to flee in the dark, which exacerbated distress for the children. Many described having to cut short routine evening activities, such as getting ready for bed. Amber, aged six years, said: "We was in the bath when it started... and I had to quickly get dried, slip some pyjamas on... and we went out the door".

Amber also talked about driving out of the flood and about her younger sister:

“She wasn't really scared because she couldn't see... but I could, because I'm older and I could see. I could see over Mummy's chair when she was driving. It was really scary".

Amber's flood story illustrates how lack of preparation and her family's hurried evacuation in the dark increased her feelings of powerlessness and fear. In Staines distress resulted from young people's fear of not knowing when the water would stop rising and whether their homes would flood. Lewis, aged 14 years, explained:

"At first me and my brother thought it was quite fun... but then it kept on going up higher and higher and it started scaring us because we didn't know what would happen next".

Confusion about types of warnings was heightened by apparently conflicting information from authorities about where flood-waters were expected. Daniel, aged 14 years, said:

“Well... they didn't give us a bad warning. They just said, 'You need a flood plan in place. You shouldn't flood, you're not in the flood area'. So we thought we'll just be prepared if anything does happen. We didn't think it was gonna come in... We were just prepared that the roads would be closed". 
This confusion led to uncertainty about what action to take or indeed whether to evacuate and then in some cases to a state of alarm, as described by 12 year old Callum:

"We stayed for a little bit, then it went up more, and then it went to the top step and Dad said, 'We need to go now. When I say now, I mean now'".

However, a conversation between two children aged nine and 10 years shows that the younger children in South Ferriby were aware that a warning had been issued and understood key features of it:

Louisa: It was only a yellow warning, wasn't it? That means that it might not flood.

John: Green means that it's absolutely fine, nowt's going to happen. Yellow means it might happen... and red means that it could be really bad...

Louisa: But it was only a yellow warning.

Therefore, it is not just a lack of understanding of warnings that can result in inaction. The disconnect between what appeared to be lower level warnings and the severity of the actual flood event also meant that families were less prepared and more vulnerable. ${ }^{6}$ As the children's stories highlight, the problem for families living in a flood risk zone during a period of frequent 'be prepared' alerts means that they must live in a state of preparation, which on a day-to-day basis is difficult to sustain.

\footnotetext{
${ }^{6}$ Following a series of public dialogues, the Environment Agency (EA) has reshaped how flood warnings are communicated (EA, 2015). Since we conducted the research flood symbols have altered, so that a yellow symbol now means 'Flooding is possible. Be prepared'.
} 


\subsection{Children's perspectives on loss}

In both locations the issue of loss was strong in relation both to the experience of the flood and the long recovery process. Children's articulation of loss included material posessions such as family photographs or the kitchen table, but also less tangible losses such as time, familiar space and social networks. Some children, like Louisa and her cousin Jane, aged nine and 10 , talked about things that were saved:

Louisa: We got all the pictures first.... You can't re-take them really, can you?

Jane: Because there could be ones, like, of my granny, and my granny's dead now...

However, many personal possessions were destroyed and children expressed this as deep personal loss and erasure of valued memories. As Louisa explained: “... like our table that we had before. It just had us learning how to write on it... pen on it... It just had memories, sort of, on it".

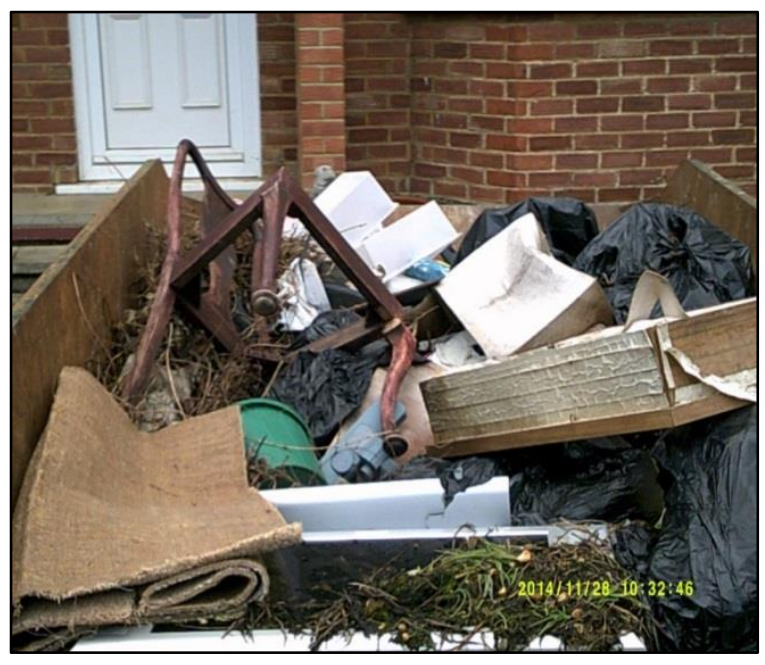

Figure 2.The skip: one of many photos taken by young people in Staines during a walk around the local floodaffected area 
Roadside skips (Figure 2) were a recurring feature, particularly in Staines, and emerged in the workshops as a powerful talking point connected to loss, waste and value. They symbolised for many how treasured possessions became soiled and dumped, along with the memories that went with them. Jodi, aged 14, talked about how "the skip of memories" that her group modelled (Figure 3) "shows the destruction the floods left.... It shows all people's memories and all their, like, precious things that got ruined".

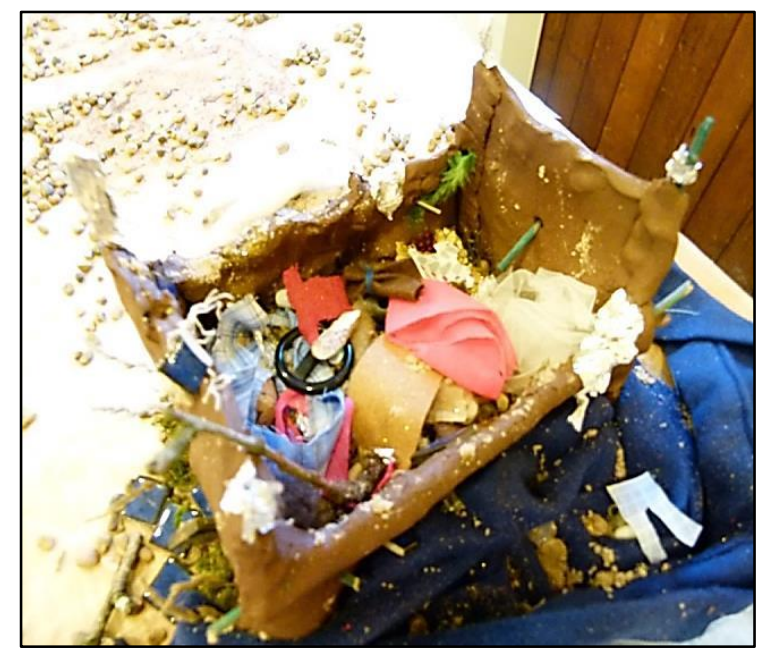

Figure 3. Group model of 'the skip of memories'

Aside from personal objects, there were stories of loss connected to the displacement experienced by the floods, including lost time. Many children and their families had to live in hotels, or were housed in other temporary accommodation, not only immediately following the flood but for long periods while their homes were being repaired. In Staines, Callum aged 12 , described how his street, currently occupied only by builders, resembled a "ghost town" that he found empty and scary, reflecting loss of familiar space. Ben, also aged 12, explained: 
"When we moved I couldn't go to the park or anything with my friends because they were all so far away... They kept on asking me but I couldn't get back, because my mum wouldn't let me cycle in the dark".

This highlights how the flood impacted on Ben's social network and friendship groups over an extended period of time, and other children in both locations echoed his experience. Andrew, aged 15, also described the loss of independence he felt when living in an hotel:

“It wasn't great... It was just weird because you don't make your own cereal or anything; they just give it to you. It's like, you want to do those everyday things".

\subsection{Children's experiences of recovery}

Coming to terms with loss was observed as an integral part of recovery. Many of the children talked about how long it can take to recover from a flood and the impact this has had on their lives, their families and the community. For some children, as Richard indicated (Figure 4) there was a desire to get "back to normal". Evacuating their homes, moving in and out with other families, or into hotels and rented accommodation, sometimes seemed an endless process. Ben, moved into rented accommodation but the tenancy ended before the building refurbishment was complete on his home, so had to move again into another rental before eventually moving back home more than a year later. 

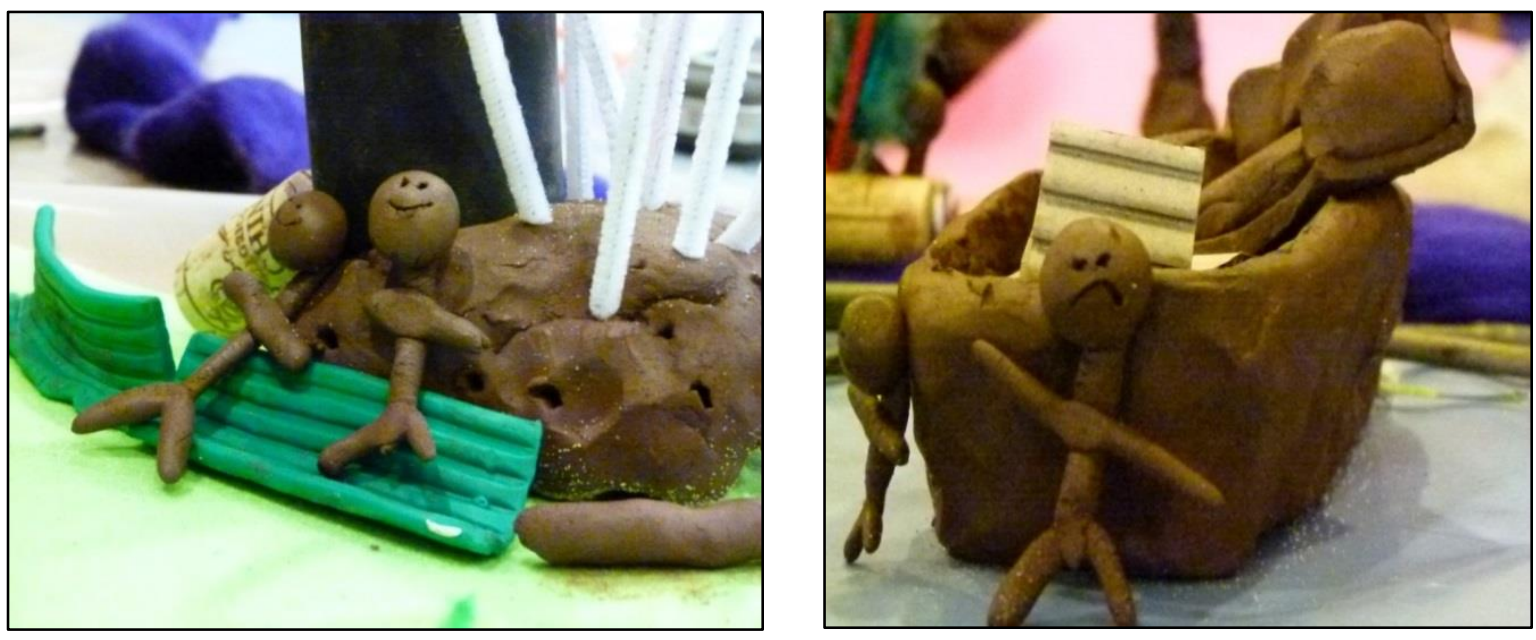

Figure 4. Models showing life before and after flooding: "I made the people, so the happy ones are for before the flood, where everything's working normally, then it's sad people for after as they have to repair everything and it takes a long time to get everything working and back to normal”. Richard, aged 14, Staines

Daniel, aged 14, was away from his home for 12 months and said: "It felt like you'd lost a year of your life". But he also talked about how living temporarily with his grandparents had brought the family closer together. Fortunately for Daniel, his grandparents' home was spacious enough to accommodate the two families, whereas Callum told us how difficult it was getting to sleep at his grandparents' home in a tiny room amongst all the packing cases and plastic bags stacked up to the ceiling full of his family's belongings:

"I could barely move in my room. I couldn't sort of get to sleep... I was so scared like [of it] falling down on me... all my stuff, Mum's stuff, everything in the kitchen, all the stuff [from] all the rooms".

He endured this situation for nine months before his family was able to return to their flat.

Children who had no relatives living locally were forced to move into often distant rented accommodation. For example, during the Staines floods children and their families were relocated to such unfamiliar spaces as an army barracks and airport hotels. Other children 
indirectly flooded, experienced 'doubling up', meaning sharing a bedroom and family home with evacuated friends and family. This became a feature of displacement:

Louisa: It was just like one big sleepover

Jane: Yes, but for a very long time.

Many of the children came to understand the processes around insurance and the general bureaucracy associated with post-flood recovery. Louisa, aged nine, from South Ferriby described how:

"We got our drying certificate on Valentine's Day.... You had to get one.... That means your house is completely dry and now you're allowed to start working in it.... Some people didn't get their houses dry... They started putting their stuff in, then it got wet again, so they had to start all over again".

However, there was dismay expressed particularly by the young people in Staines about the treatment of children and families by insurance companies and loss adjustors. They noticed that different companies took different approaches and as Jodi, aged 14, pointed out this varying treatment seemed unfair: "If your insurance were nice enough to give you a skip, then you were so grateful, you were so lucky".

Having a skip (or not having one) is an example of how contradictions between the wider insurance industry and its supply chains may cause added stress to families and this exposed children to new levels of unfairness. Children talked about having to throw things out rather than restore them, and concerns about whether their insurance meant their homes would be made safer or more protected in the future. In this way, injustice became materialised for them. 


\subsection{Children's awareness of isolation}

Young people, predominently in the Staines group, explained how in the months following the flood they began to feel isolated. Unlike the primary school group, in a large school community it was possible never to hear about others, especially in different year groups, who had been flooded at home. Added to this, the young people felt that the majority of the school staff were unaware which pupils were flood-affected and this seemed to have increased their sense of isolation. We return to this point below. However, in a large school which itself is not flooded, a sense of being alone and struggling to manage schoolwork can build up. An expample of this was described by Andrew aged 15, who told us about the frustration of being unable to submit his GCSE options form because of the lack of access to computing and internet in the hotel where his family were housed: “ ... I couldn't even fill out the form because it was online. I couldn't print it out".

Establishing who is affected, and the extent of the problems, is more complex than traditionally collected flood statistics suggest. The complexities of being directly and indirectly flood-affected are apparent from the children's experiences outlined in our findings. Perhaps unsurprisingly, they reported a sense of isolation, with no-one to talk to who seemed to understand their situation; they had to manage the long-term effects of living in temporary accommodation, losing friendships if they had to re-locate to a different school because of home displacement, and had to cope with family tensions exacerbated by floodrelated financial worries. 
In these ways, children were seen to find the flood experience, from the day of the flood through the long recovery period, not only isolating but alienating - a feeling underlined when they found that friends, schools and local authorities failed to notice what they were going through, and consequently were unable to provide support.

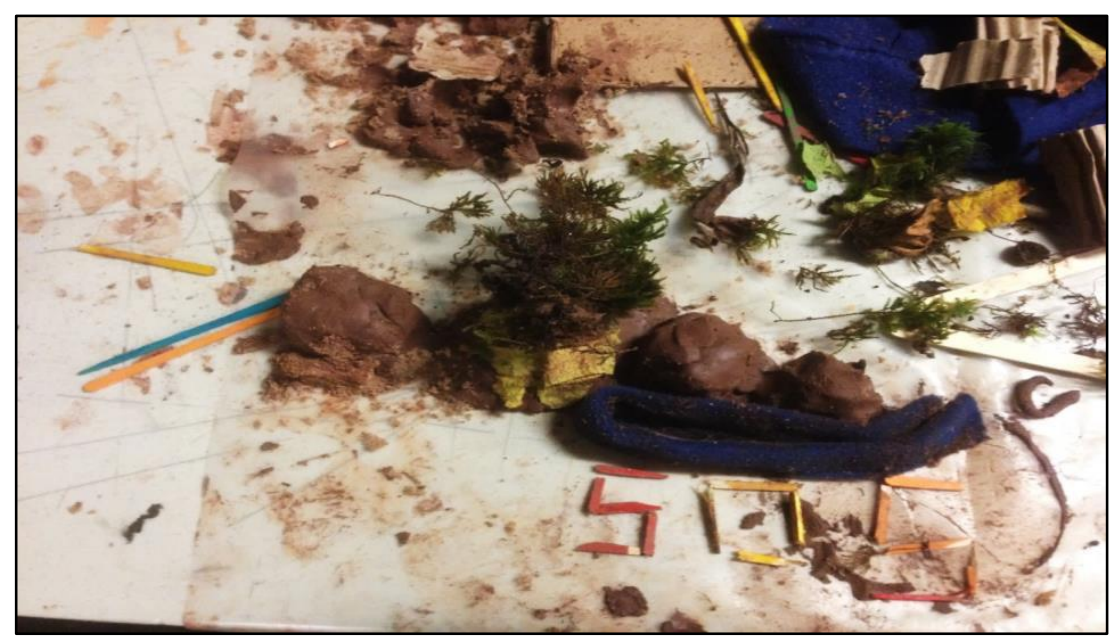

Figure 5. Ruth's model signals 'SOS'

A recurring theme among the young people in the Staines workshops was a sense of abandonment during the crisis by those they felt ought to be supporting them, as Ruth's model (Figure 5) 'SOS' demonstrates. Ruth talked about how many local people were left to "fend for themselves" by the authorities and she later described how:

"My experience left me with the feeling of being on our own and it felt like no one cared. It felt like we weren't helped until it was too late".

Ruth's workshop model demonstrated what she saw as a strong injustice - e.g. that some people were given sandbags while others were not - leaving her with a sense of connection with others who had not been helped during the flooding. As the workshops progressed, 
children in both locations remarked on what taking part in the project meant for them.

Daniel, aged 14, commented:

"Everyone in here like understands what you went through, so you can talk to them and you know that they're okay with listening, whereas outside they haven't been through it. Because you sometimes feel like, if you're talking it, you're droning a bit and it's boring them... whereas in here we kind of connect a bit more".

However, children need both the chance to talk to their 'flood peers' and to articulate their concerns to the wider world. After the stakeholder perfomance event, the young people at Staines talked enthusiastically about being able to communicate their experiences and ideas to others:

Ruth: It feels good. It feels like we finally have a voice.

Sara: Yeah, like we can be heard now; like, they know how we feel.

However, it is not enough to listen to children if nothing then changes. Pledges for action were made by audience members to the children following their presentations in South Ferriby and Staines, and later to the national Flood\&Coast 2016 delegates at the annual Environment Agency convened conference. In order for children to realise their right to participate and their wider citizenship, it is necessary for policy makers and practitioners to 'listen strategically' (Kashefi and Mort, 2004) to what they have to say and then find ways to respond, developing flood preparation, recovery and resilience measures accordingly. 


\subsection{Children as active contributors in flood response and recovery}

Given the general lack of acknowledgement in flood and emergency planning policies of children's capacities to contribute to and support their local communities, we were interested to hear from the children about what they actually did during the floods. We learned that many had been actively engaged both in the immediate response during the flood events, and in the recovery process, supporting their families, friends and local communities in a range of ways. We heard accounts of how children checked in on neighbours, helped to move their own and other people's furniture upstairs and joined in with the clean-up. They said this was generally a positive experience and they expressed satisfaction about the times they had been able to support others in difficulty. For example, Sara, aged 14 , served tea and coffee to evacuated families and rescue teams at her local village hall: "I felt quite good at myself then. I could have been home just watching TV and I was actually constructive and helping people". School friends Avril and Helena, aged nine and 10 gave up a riding lesson to help clean up their friend's house: "No way would we have let our friend have to do it all herself... because we would be guilty. We didn't even have to make a choice".

In the course of the workshops, it also became apparent that children knew and understood more about what was happening than adults sometimes realised. Children described instances of seeing the pressure and strain in the adults around them, even when parents and teachers believed they were shielding the children from what was happening. Many of the children talked about the impact of the experience on their families and friends and demonstrated empathy and understanding for the reactions of others during the flood and the recovery process. As with the findings about the alienating effects of the floods, children 
are sometimes further excluded by the very fact of being children. But as 10 year old Helena told the audience at the stakeholder event in her school: "Adults need to know that children become more scared and worried when they do not know what is happening... children have the right to know".

\subsection{Children's understandings of flood adaptation and new normalities}

In both locations children talked about the likelihood of repeated flooding. To some extent this concern seemed to be related to a raised level of anxiety about the prospect of future flooding. As Jodi, aged 14, explained:

"I'm just kind of like worried it's going to happen again this year... I suppose I'm going to worry every year though. Even if it doesn't happen, we're still going to worry".

Such concerns were shared by many of the other children, who demonstrated a high level of what could be called 'flood awareness'. This means that drawing on their experience, they bring valuable knowledge and understanding of flooding which is helpful in developing community preparedness and resilience. For example, during walks around the local floodaffected area, the children identified clues in the landscape as to flood risks and spaces for flood management. In the workshops they discussed measures that would need to be put in place to help communities be better prepared for 'next time'.

Critically, while there was a desire for a return to 'normal' after the floods, many children demonstrated an understanding of the need for families and communities to adapt to a 'new normal' that ensured they were prepared. As Richard explains (see Figure 6): 
"It's a little raft and there's a person sitting on it. They're all prepared... They didn't realise that it would have ever flooded but now they realise that it will more than likely flood again, so they've bought themselves a little raft that I made... Because it's happened before, it can happen again. They're adapting...".

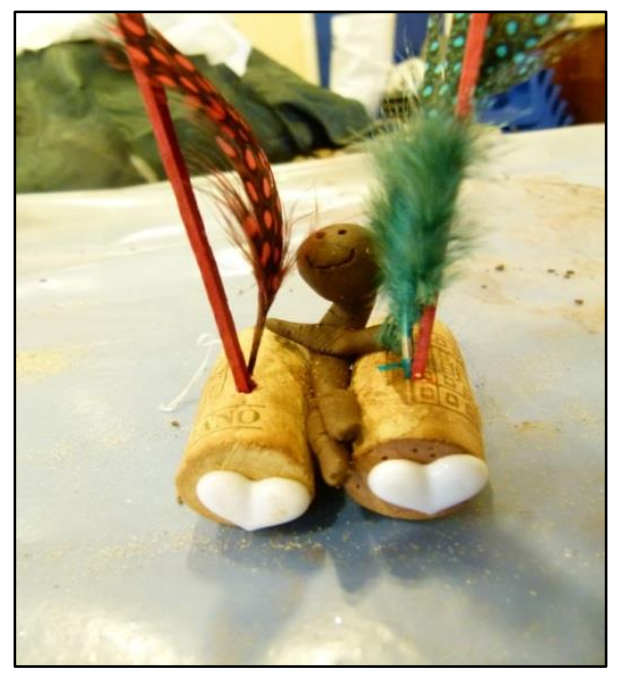

Figure 6. Richard's model of a raft

In South Ferriby, a number of children talked about how, since the floods, their families had put together a flood plan and several talked about the measures their parents had taken to better prepare their homes. Britney, aged eight, described her family's plans:

“We've sorted out next time. We've got a flood toilet... The floodwater can't go inside it... And then we're gonna turn all the lights off... and we're gonna go upstairs. And then we're gonna take our neighbours upstairs to my mum and dad's room and then we're gonna put some candles on.... And we're gonna get loads of food".

However, in contrast, some of the children were aware that many people in their community had not taken measures to prepare for next time and just wanted to get back to 
normal. As Daniel, aged 14 points out: ".....people do kind of forget about what it was like a year ago... They forget it could happen again".

Children expressed an understanding that what counts as normal has in fact changed. They recognise that there is a 'new normal' which includes flooding and taking measures to prepare for and adapt to flood events.

\section{Developing Flood Manifestos for Change}

At the third workshop, having identified many of the problems they experienced during and following the floods, the children developed Flood Manifestos, actions that they, their families, communities and government should take to be prepared and better manage future events. This was a major step from being affected to being effective, or as we might put, it from victims to actors.

As actors then, the children presented their ideas for change at performance-based events to audiences of parish and district councillors, and then with growing confidence to the insurance sector, emergency services, health and social care professionals, representatives from the Environment Agency, Defra and the Cabinet Office-Civil Contingencies Secretariat, teachers and parents. The interactive presentations were based around a game of 'snakes and ladders', drawing upon a range of material produced or provided by the children over the course of the project. The audience was taken through a 'flood story' to demonstrate how experiencing and recovering from floods is often arbitrary and never a linear process. Children gave out their Flood Manifestos and invited audience members to respond by 
writing a pledge about what action they would take as a consequence. A six-minute film captures the key points from this process and helps the Manifestos reach a wider audience. The Manifestos call for improvements in essentially three flood policy and practice domains - recovery, resilience and education (we have retained most of the children's original words in Table 1 and the full documents and film can be viewed on the website:

www.lancaster.ac.uk/floodrecovery. 


\section{Recovery, health and wellbeing}

- Recognise that floods cause poverty. Displaced families need help with the extra cost of food, washing clothes and transport

- Set up groups in schools for children who have been affected by floods, so they can talk and get support

- Recognise that floods can lead to poor health, such as bad diets if people can't afford healthy food or don't have the means to prepare it

- Disabled people need more specialised help before, during and after a flood

- Make insurance fairer

\section{Resilience and flood preparedness}

- There should be more grants to help make homes more resilient and help with bureaucratic red tape

- Support the development of community flood fund initiatives - to help people who are flooded, or may be in the future

- All families and communities should have a flood plan

- Flood warnings need to be clearer, so people understand them, and know what to do and when to act

- Awareness should be raised using different forms of media; information should be put up in the community, as it is for fire safety

\section{Flood education}

- Flood education should be given in all schools, from Reception level onwards.

- There should be lessons on emergencies and flooding: how to prepare, understanding priorities when it floods, where to go, survival and first aid.

- Include 'flood tests', and flood simulation events (similar to fire drills). Develop flood preparation games

- Teachers need training about floods, and how they affect children and their education

Table 1 Key points from the Manifestos

Researching with flood-affected children makes what happened visible in new ways. The children's models, their stories, their Flood Manifestos, their performance at stakeholder events, and the project film show the complexity and heterogeneity of what it means to be flood-affected. They are also an expression of children's citizenship based on practice and action, rather than theory or abstract rights, as explored by Larkins in her work with groups 
of children from marginalised communities in Wales and France (Larkins 2014).

Unfortunately flood policy in England is currently too fragmented across government departments and agencies because of complex (sometimes historical) divisons of responsibility. This fragmentation tends to act as a block to the adoption of 'bottom-up' innovative and creative proposals such as made by the children, for raising flood awareness, addressing flood risk and assisting with flood recovery. The Manifestos reveal key gaps in flood policy and practice and highlight the need to 'join up the dots' across government departments and agencies. We argue that in order to implement what are in effect urgent demands by the children, a fundamental shift is required in the way policy is conceived, one that recognises children's citizenship and right to be heard. The Manifestos demonstrate a number of policy implications:

1. Flood recovery and resilience must be seen as central to government in order to meet the needs of children and young people: this means involving education, health, housing, communities and local government in addition to emergency planning and flood risk management.

2. Flood policy and practice in England as currently organised, is confusing and over complex, reducing ability to address the recovery and resilience issues identified by children and young people in this project.

3. Where flood-affected children and young people are enabled to contribute their experience to flood risk management, this enhances their own recovery and resilience.

4. All children and young people are citizens in their own right and have a role in flood risk management and a right to help build family and community resilience.

5. Flood risk management will be more robust and demonstrate greater legitimacy by drawing on children and young peoples' perspectives.

Table 2 Policy implications derived from the children's perspectives 


\section{Discussion}

Our research shows children play an important role in flood response and recovery, actively helping their families, neighbours and the wider community. Children recognise the risk of future flooding often more readily than adults, which prompts them to think about adaptation and the need for a 'new normal' (see Harms, 2015 for further discussion relating to the benefits of adopting a 'new normal'). Flood-affected children in our study expressed interest in having a more explicit role in developing flood prevention and preparedness in their communities and families and our research highlights that having an active role in this helps with recovery. Their participation and responses to this research shows that children can be powerful advocates for change in flood risk management.

Recognising the value of children's perspectives and capacities would clearly make flood policy more effective, enhance resilience and reduce the impact of future emergencies. Not to consult with children about resilience building is to fail to take advantage of their experience and particular perspectives. To recall just one example, when Andrew told us about not being able to access his GCSE options form online because of being displaced by the flood. This was clearly something that the school authorites had not anticipated and it demonstrates the wider complex vulnerabilities of a society now so heavily dependent on the internet and on sources of electricity which can fail in a flood (Kemp, 2015). The frequently quoted UN Convention on the Rights of the Child states that children have the right to be heard and actively participate in decision-making that affects their lives. However, our research, along with that of James (2011) and Larkins (2014) shows an imperative to move beyond rehearsal of rights (useful though this is). Drawing on the work of Isin, Larkins goes on to make a distinction between 'actions', and 'Acts' of citizenship. In 
our study, actions would include helping flooded neighbours, while Acts would include creating and presenting the Flood Manifestos. Lack of recognition of children's roles in disasters serves them badly, as Helena told the audience of stakeholders that came to her school: 'Children have the right to know' As a first step, this marginalisation could be addressed by actively involving children in disaster risk reduction activities and ensuring that children have equal access to meaningful information on flooding.

The children who took part in this project are flood experts from their own understanding and experience of what it means to be flood-affected. As their Flood Manifestos demonstrate, the negative impact of floods on children is exacerbated by inadequate flood risk management by adults; the organisational complexity brought about by recent flood policy changes and undermines the ability to address this. The Flood Manifestos are a call to action, but we are concerned that flood policy in England (preparation, response, recovery, resilience) is currently too fragmented to enable children's concerns to be fully addressed, as the multiple effects of flooding are the domains of different government departments or agencies. For example, the children asked to learn more about flooding in school with regard to safety and flood risk to their communites, but it is unclear which department has the mandate to address this need - whether it is the Department for Education, the Department for Communities and Local Government or the Department for Environment, Food \& Rural Affairs. While some educational resources about flooding have been developed for children it is far from clear how these will or can be adopted (Defra, 2016). Opportunities to respond to children's actions and Acts of citizenship get lost in bureaucracy. 
This paper adds to a growing body of work which attends to the multiple (social, technical and political) dimensions of flooding (Walker et al 2011; Twigger-Ross et al, 2015; Butler et al, 2016), but in particular the marginalisation of children and young people who are affected, but largely excluded from being effective. Recent research recognises that floods are complex, heterogenous and have multiple effects; that they can be heavily localised, yet relate to distal, global phenomena. Floods are about rainfall, catchment, urbanisation, infrastructure, investment, climage change and they are about people - from issues of human-induced environmental change to trust in flood warnings; from Property Level Protection measures to social solidarity and cohesion.

Flood events in the UK bring all the above issues to the surface, and while there have been examples of supportive, tireless and innovative practice on the ground, we believe that the policy response to this increasing complexity over the last three major disasters (2007 2015/6) has been inadequate. Butler et al's research (2016) on public perceptions of the 2013/4 floods reports a "lack of clarity about institutional responsibilities" (page 3) and also that flood-affected people expect their government to protect them against flooding, to mitigate it and coordinate the response to it, while acknowledging they (the public) also have, and do, play a role (page 23). But protection, mitigation, response (and the often neglected area of 'recovery') are all located in different organisational domains, between different agencies and government departments. This fragmentation is no more a naturally occurring phenomenon than is contemporary flooding, but is the outcome of a series of decisions in favour of 'localising' responsibilities under successive governments and which have been severely criticised (Begg et al, 2015). 
Working with children underlines that it is time to find a way to reach across organisational boundaries and redirect resources to bring together flood response, recovery and resilience. An optimistic reading of recent events suggests that a more joined up approach to flood policy may be gaining ground: the 2016 National Flood Resilience Review drew from a multiagency advisory committee (though it omits any role for children or young people) and the Environmental Audit Committee recently carried out an inquiry termed 'Cooperation Across Government'(2016). But the remits of both these inquiries were still heavily shaped around issues of infrastructure and investment, and entirely from an adult perspective. A reading of the children's Flood Manifestos points to creative and imaginative ways to 'join the dots' in flood risk management linking three key policy domains: recovery, health and well-being; resilience; and preparedness and flood education. The children's sustained work for this project was based on their hard won experience and ability to reflect and extract messages for policy; it demonstrates their determination to be seen as actors rather than passive victims.

\section{Acknowledgements}

We are very grateful to the two schools and their staff, and in particular to the children and young people who took part, without whom this study could never have taken place. The research was funded by the Economic and Social research Council (Grant No ES/M007367/1) 


\section{References}

Back E, Cameron C, Tanner T, 2009 Children and Disaster Risk Reduction: Taking stock and moving forward UNICEF Children in a Changing Climate

Begg C, Walker G, Kuhlicke C, 2015 Localism and flood risk management in England: the creation of new inequalities? Environment and Planning C: Government and Policy 33 685702

Bingley A F, 2003 In here and out there: sensations between self and landscape Social and Cultural Geography 4 (3) 329-345

Bingley A F, Milligan C, 2007 Sandplay, clay and sticks: multi-sensory research methods to explore the long-term influence of childhood play experience on mental well-being Children's Geographies 5 (3) 283-296

Butler C, Walker-Springett K, Adger W N, Evans L, O'Neil S, 2016 Social and political dynamics of flood risk, recovery and response Exeter: The University of Exeter Cabinet Office, 2015 National Risk Register of Civil Emergencies London: Cabinet Office Cabinet Office, 2016 Human Aspects in Emergency Management, Guidance on supporting individuals affected by emergencies London: Cabinet Office

DCMS, 2006 Humanitarian Assistance Strategic Guidance- Building capability to look after people affected by emergencies London: Department for Culture, Media and Sport

Defra, 2016 Defra Flood Resilience Community Pathfinders Scheme 2013-15 National Flood Forum: Bewdley 
Defra and Cabinet Office, 2016 National Flood Resilience Review Policy Paper, London: Defra Duke of Cornwall Community Safety Award, 2012 About the Award Cornwall Fire, Rescue and Community Safety Service: Cornwall Council

Easthope L, Mort M, 2014 Technologies of recovery: practices and entangled politics in disaster The Sociological Review 62 (1) 135-158

Environment Agency \& Cumbria Floods Partnership, 2016 Reducing Flood Risk from Source to Sea: First steps toward an integrated catchment plan for Cumbria Bristol: Environment Agency

EA, 2015 Public dialogues on flood risk communication Final Report - SC120010/R1, Bristol: Environment Agency

EAC, 2016 Flooding: Cooperation across Government, Second Report of Session 2016-17 London: House of Commons Environmental Audit Committee

Erikson K, 1978 Everything in Its Path: Destruction of Community in the Buffalo Creek Flood New York: Simon \& Shuster

Erikson K, 1994 A New Species of Trouble: the human experience of modern disasters New York: WW Norton

Erikson K, 2008 Preface to (Convery I et al) Animal Disease and Human Trauma: Emotional Geographies of Disaster Basingstoke: Palgrave Macmillian

Essex Civil Protection \& Emergency Management, 2014 What if...? Essex: Essex County Council and Essex Resilience Forum

Fothergill A, Peek L, 2015 Children of Katrina, Austin: University of Texas 
Freeman C and Aitken-Rose E, 2005 Future shapers: children, young people, and planning in New Zealand local government, Environment and Planning C: Government and Policy, 23, 227-246.

Gibbs L, Mutch C, O'Connor P and MacDougall C, 2013, Global Studies of Childhood, 3, (2), $129-141$

Harms L, 2015 Understanding trauma and resilience, London: Palgrave HM Government, 2004 Civil Contingencies Act Her Majesty's Government, London: Cabinet Office

IFRC, 2010 World Disasters Report - Urban Risks Geneva, Switzerland: International Federation of Red Cross and Red Crescent Societies

IPCC, 2014 Summary for policymakers. In: Climate Change 2014: Impacts, Adaptation, and Vulnerability. Part A: Global and Sectoral Aspects. Contribution of Working Group II to the Fifth Assessment Report of the Intergovernmental Panel on Climate Change [Field, C.B., V.R. Barros, D.J. Dokken, K.J. Mach, M.D. Mastrandrea, T.E. Bilir, M.Chatterjee, K.L. Ebi, Y.O. Estrada, R.C. Genova, B. Girma, E.S. Kissel, A.N. Levy, S. MacCracken, P.R. Mastrandrea, and L.L. White (eds.)]. Cambridge University Press, Cambridge, United Kingdom and New York, NY, USA, pp. 1-32

James A, 2011 To Be (Come) or Not to Be (Come): Understanding Children's Citizenship, The Annals of the American Academy 633, 167-179

Jenkins K, Surminski S, Hall J, Crick F, 2016 Assessing surface water flood risk and management strategies under future climate change: an agent-based model approach, 
Grantham Research Institute on Climate Change and the Environment Working Paper No.

223 London: London School of Economics and Political Science

Kashefi E, Mort M, 2004 Grounded Citizens Juries: a tool for health activitsm? Health

Expectations $74290-302$

Kemp R, 2016 Living Without Electricity: one city's experience of coping with loss of power

London: Royal Academy of Engineering

Larkins C, 2014, Enacting children's citizenship: Developing understandings of how children enact themsevles as citizens through actions and Acts of citizenship, Childhood, 21, 1, 7-21

Lave J, Wenger E, 1991 Situated Learning: Legitimate Peripheral Particpation Cambridge, Cambridge University Press

Messling, L, Corner, A, Clarke, J, Pidgeon, NF, Demski, C, Capstick, S, 2015 Communicating flood risks in a changing climate Oxford: Climate Outreach

Medd W, Deeming H, Walker G, Whittle R, Mort M, Twigger-Ross C, Walker M, Watson N, Kashefi E, 2015 The flood recovery gap: a real-time study of local recovery following the floods of June 2007 in Hull, North East England Journal of Flood Risk Management 8 (4) 315328

Mellor, D Leigh M, Dumbarton, D, Smith S, Howells, G, 2014 Neither seen nor heard:

planning for the unique needs of children in an emergency Save the Children, UK and Cabinet Office Emergency Planning College 
Mutch C and Gawith E 2014, The New Zealnad Earthquakes and the role of schools in engaging children in emotional processing of disaster experiences, Pastoral Care in Education, 32:1 54-67

Public Health England, 2014 Guidance on Recovery from Flooding, Essential information for frontline responders London: Public Health England

Rodriguez-Giralt I, Lopez D, Arenas M, 2016 Scoping and Review Report on evidence of chdirlen, Young people, disasters and participation CUIDAR: XXX Unviersity

Stephens S, 1996 Reflections on Environmental Justice: Children as Victims and Actors Social Justice 234 (66) $62-86$

Thorne C,2014 Geographies of UK flooding in 2013/4 The Geographical Journal 180 (4) 297309

Twigger-Ross C, Orr P, Brooks, K, Sadauskis, R, Deeming H, Fielding J, Harries T, Johnston R, Kashefi E, McCarthy S, Rees Y, Tapsell S, 2015 Flood Resilience Community Pathfinder Scheme Evaluation, London UK: Department for Environment, Food \& Rural Affairs OHCHR, 1989 Convention on the Rights of the Child Geneva, Switzerland: Office of the United Nations High Commissioner for Human Rights

Walker G, Whittle R, Medd M, Walker M, 2011 Assembling the flood: producing spaces of bad water in the city of Hull Environment and Planning A 43 2304-2320

Walker M, Whittle R, Medd W, Burningham K, Moran-Ellis J, Tapsell S, $2010 \underline{\text { Hull Children's }}$ Flood Project Final Report XXX, UK: XXX University 
Walker M, Whittle R, Medd W, Burningham K, Moran-Ellis J,Tapsell S, 2012 'It came up to here': learning from children's flood narratives Children's Geographies 10 (2)135-150

Whatmore S, Landstrom C, 2011 Flood apprentices: an exercise in making things public Economy and Society 404 582-610

Whittle R, Medd W, Deeming H, Kashefi E, Mort M, Twigger Ross C, Walker G, Watson N, 2010 After the Rain - learning the lessons from flood recovery in Hull XXX, UK: XXX University

Whittle R, Walker M, Medd W, Mort M, 2012 Flood of emotions: emotional work and longterm disaster recovery Emotion, Space and Society 5 60-69

Maggie Mort is Professor in the Sociology of Science, Technology \& Medicine at Lancaster University. She is Coordinator of the EC Horizon 2020 project CUIDAR: Cultures of Disaster Resilience Among Children and Young People, and the ESRC Children, Young People and Flooding research project. She teaches and supervises in disaster studies, health policy and practice, patient safety and medical uncertainty and has published widely on technological change in health and social care, and on health and social consequences of disaster.

Dr Marion Walker is a human geographer and a Senior Research Associate in Sociology at Lancaster University. Marion's research interests are the geography of education, research with children and young people, and working with innovative methodologies. She has extensive research experience of working with flood-affected families in the UK and led the research on the Hull Children's Flood Project following the severe floods of 2007.

Dr Alison Lloyd Williams is a Senior Research Associate in Sociology at Lancaster University. Her research interests are the uses of theatre in education and development and, more recently, disaster resilience. She has worked on school and community projects in the UK, 
Japan and a number of African countries and developed the use of performance methods on the ESRC Children, Young People and Flooding project.

Dr Amanda Bingley is a Lecturer in Health Research in the Faculty of Health and Medicine, Lancaster University. Her work focuses on the relationship between mental health, wellbeing and place, including the effects of woodland and natural spaces on mental health in young people, research with older people, and the benefits of gardening, woodland workers, and older conservation volunteers. Her particular interest is in ethnographic, participatory arts research methodologies informed by her background in psychoanalytic geographies. 